\title{
The enigma of cuboid diamonds: the causes of inverse distribution of optical centers within the growth zones
}

\author{
Evgeny A. VASILEV ${ }^{1 *}$, Dmitry A. ZEDGENIZOV², Igor V. KLEPIKOV³ \\ ${ }^{1}$ Saint-Petersburg Mining University, 2, 21 line, Saint-Petersburg, 199106, Russia; simphy12@mail.ru \\ 2 Sobolev Institute of Geology and Mineralogy, Russian Academy of Sciences, Siberian Branch, 3, Koptyuga ave, Novosibirsk, \\ 630090, Russia \\ ${ }^{3}$ A.P. Karpinsky Russian Geological Research Institute, 74, Sredny prospect, Saint-Petersburg, 199106, Russia \\ * Corresponding author
}

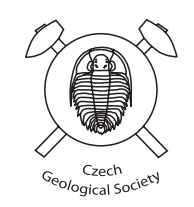

In the present work, diamonds with yellow cores and a slightly colored or colorless rims have been studied. Three groups of crystals that differ in spectroscopic features have been identified. In the crystals of the first group, the heterogeneity in color is due to the variation in nitrogen concentration, which is present as the simplest low-temperature nitrogen $\mathrm{C}$ center. Absorption spectra of the first group display peaks at wavenumbers 1344 and $1332 \mathrm{~cm}^{-1}$ of $\mathrm{C}$ and $\mathrm{C}+$ centers, respectively. The second group also exhibits higher nitrogen concentrations in the form of $\mathrm{C}$ centers in the colored zone. However, the concentration of nitrogen in the form of high temperature A-centers, and the total nitrogen content is higher at the periphery of crystals. The FTIR absorption spectra of this group display both 1344 and $1332 \mathrm{~cm}^{-1}$ peaks. Crystals of the third group do not contain C centers. The $1332 \mathrm{~cm}^{-1}$ and the A center bands are observed in the FTIR absorption spectra. In the photoluminescence spectra of the colored zone of the third group, the bands S1 and S2 have been found and the doublet lines 883 and $885 \mathrm{~nm}$ of the simplest Ni-containing centers. Previously unobserved systems with zerophonon lines at 799.5, 819.6, 869.5 and $930 \mathrm{~nm}$ lines have been registered in the photoluminescence spectra of the third group under $787 \mathrm{~nm}$ excitation. It is hereby proposed that this luminescence is due to Ni-containing centers. In the third group of crystals, Ni seems to stabilize $\mathrm{C}+$ centers and hence the coloring of crystal zones is consistent with $\mathrm{Ni}$ impurity distribution. Crystals of each group have distinct sources: the first group is from Yubileinaya pipe, the second from the placers of North Yakutia with unknown primary sources and the third from the Uralian deposits.

Keywords: FTIR, photoluminescence, nitrogen, nickel

Received: 30 October 2019; accepted: 24 March 2020; handling editor: R. Škoda

The online version of this article (doi: 10.3190/jgeosci.301) contains supplementary electronic material

\section{Introduction}

Most diamond crystals are zoned, due to variations in growth conditions and environmental composition or oscillations in impurity contents. These heterogeneities are complicated by secondary processes upon natural annealing. The central zone of diamond crystals is subjected to annealing for the longest time, while the peripheral zone records the lowest temperature and duration of natural annealing. This pattern is well-defined in the distribution of nitrogen crystal structure defects (Bulanova et al. 2002; Vasilev and Sofroneev 2007; Kohn et al. 2016). Total nitrogen concentration in a diamond may be over 3000 ppm (Zaitsev 2001). Single substitutional nitrogen atom $\mathrm{C}$ is the simplest growth defect; it is the cause of yellow color (Collins 2001; Zaitsev 2001; King et al. 2005). Upon annealing, $\mathrm{C}$ centers are transformed into more complex A centers that are, in turn, transformed into B and N3 centers. As a result of such transformations, the color disappears. A centers consist of two nitrogen atoms; $\mathrm{N} 3$ and B centers consist of three and four nitrogen atoms and a vacancy $\left(\mathrm{N}_{3} \mathrm{~V}, \mathrm{~N}_{4} \mathrm{~V}\right)$ respectively. The concentrations of $\mathrm{A}, \mathrm{B}$ and $\mathrm{C}$ centers are estimated by Fourier Transform Infrared (FTIR) spectroscopy. Crystals having a yellow periphery with $\mathrm{C}$ centers are not rare (Kamiya and Lang 1965; Boyd et al. 1987; Yelisseyev et al. 2004; Gubanov et al. 2019; Lai et al. 2020). Such crystals may have a structurally discernible core and a mantle. The periphery sometimes does not clearly differ in structure from the core but has a yellow color and contains $\mathrm{C}$ centers (Hainschwang et al. 2006). Cuboid diamonds often have dominantly A and B centers in the center of the crystal and C centers in the periphery. Such crystals are formed by [100] pyramids with the normal growth mechanism. The cuboids typically show a low degree of nitrogen defect aggregation. Crystals with "inverse" zoning have been discussed in a few works in recent years (Zedgenizov et al. 2016; Smit et al. 2018; Timmerman et al. 2018; Klepikov et al. 2019). In these crystals, the core is yellow, and their periphery is pale-yellow or colorless. Such "inverse" zoning is not consistent with the generally accepted notion of nitrogen defect transformation. With 
aim to better understand this "inverse" zoning phenomenon, cuboid diamonds with a yellow central zone from Russia have been studied in the present work using FTIR and photoluminescence (PL) spectroscopy.

\section{Materials and methods}

Crystals with a yellow central zone and a pale-yellow or colorless periphery were selected for the current study. These were crystals of cubic habit or fragments of cuboids from the Uralian placers (Klepikov et al. 2019), from the Yubileinaya kimberlite pipe and from Istok placer in the Anabaro-Oleneksky interfluve, Russia (Zedgenizov et al. 2016). Plates of 0.4-0.7 mm thickness were cut out from the crystals through the center in the plane $\{100\}$ and polished.

Absorption spectra were recorded using a Vertex 70 spectrometer with a Hyperion 1000 microscope at a resolution of $1 \mathrm{~cm}^{-1}$ and averaged from 32 scans in the range of 600 to $7000 \mathrm{~cm}^{-1}$. The aperture size was $100 \times 100$ $\mu \mathrm{m}$; in general case, true location does not exceed the third of the plate thickness with standard IR $15 \times$ objectives. For thin light zones (as in plates Ubk-2, Ubz-15), the spot size was decreased down to $20 \times 100 \mu \mathrm{m}$. Because of relatively thick plates we did not use a smaller aperture. In the range of 500 to $1100 \mathrm{~nm}$, the spectra were recorded at room temperature at a resolution of
$8 \mathrm{~cm}^{-1}$ and averaged from 1000 scans. In the range of 390 to $650 \mathrm{~nm}$, absorbance spectra were recorded at room temperature on a Renishaw In Via spectrometer at a resolution better than $0.12 \mathrm{~nm}$, averaged from 10 scans in step mode, with a $12 \mathrm{~V}, 100 \mathrm{~W}$ halogen lamp as a light source, a L50 $\times$ objective. In this mode, the edge filter was removed from the spectrometer and the entrance slit width was set to $15 \mu \mathrm{m}$. In order to shift spectral range to low wavelength, a CC8 color filter was mounted in front of the slit. To compare color brightness, the absorbance at $450 \mathrm{~nm}\left(\mathrm{a}_{450}\right)$ was measured in each spectrum with constant baseline subtraction at 650 $\mathrm{nm}$. The calculation of true value of absorbance at 450 $\mathrm{nm}$ is complicated by scattering on inclusions (samples Ubk 1-7, Ubk 1-2, Ubk 2, HL-3, ISTD 28, ISTD 3) and reflectance from cracks (samples Ubk 1-2, U 601). Both scattering and reflection gave a rise in registered absorption spectra towards lower wavelength. Automatic baseline subtraction, normalizing and manual simple FTIR spectra decomposition were performed via "Spectrexamination" application, developed in ALROSA Co. by $\mathrm{O}$. Kovalchuk. Nitrogen concentrations in the form of $\mathrm{A}\left(\mathrm{N}_{\mathrm{A}}\right)$ centers were calculated from known proportionality coefficients (Boyd et al. 1994). The absorption of B centers with main peaks at 1010, 1170 and 1332 $\mathrm{cm}^{-1}$ was not revealed in the studied crystals. The main peak of $\mathrm{C}$ centers at $1135 \mathrm{~cm}^{-1}$ was not used for calculation of $\mathrm{C}$ centers concentration, because of a significant

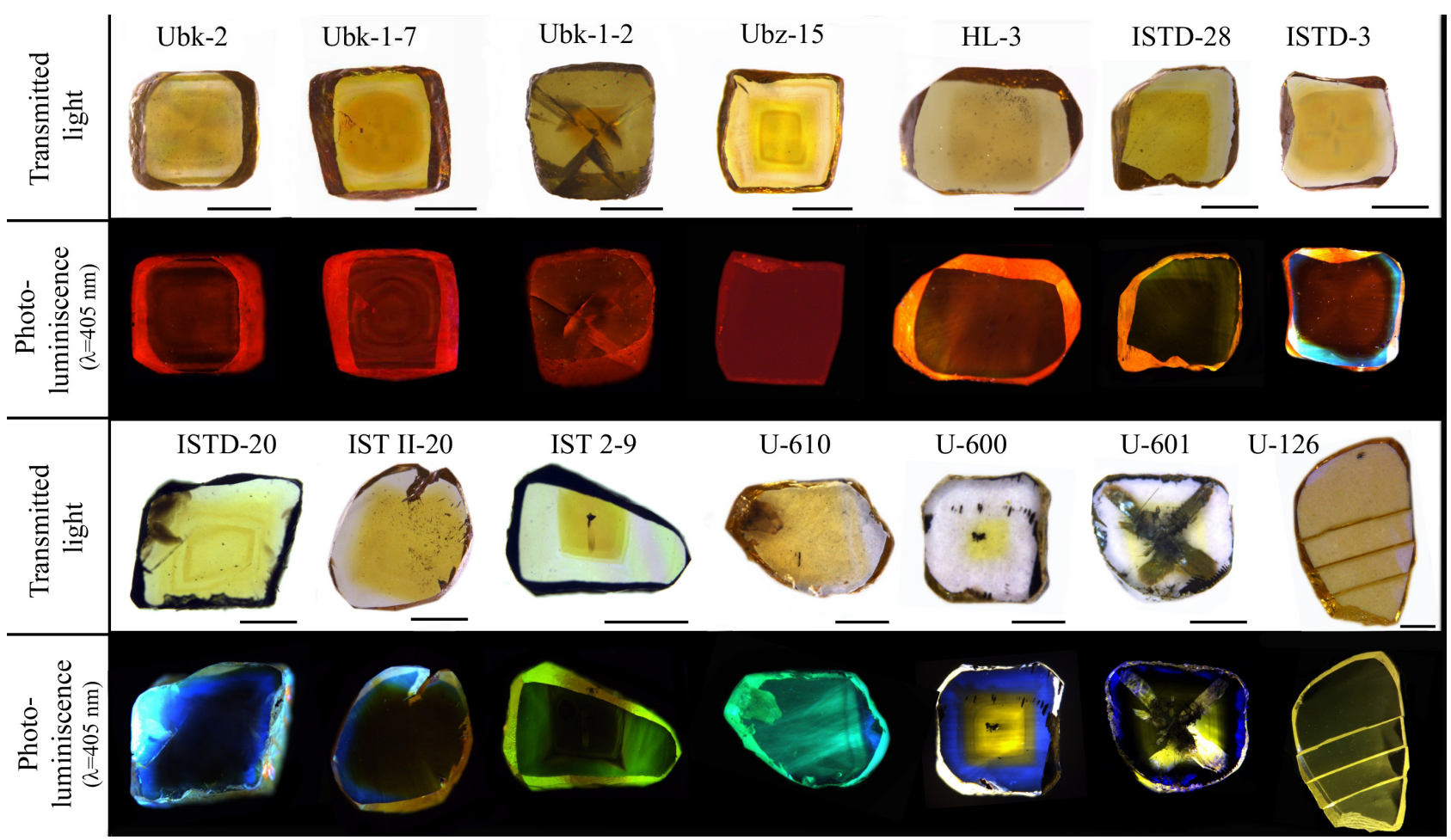

Fig. 1 Images of the studied diamond plates in transmitted light and in photoluminescence (405 nm excitation with $450 \mathrm{~nm}$ longpass edge filter). The length of the scale bar is $1 \mathrm{~mm}$. 
background of other bands at this range. A absorption coefficient of the peak $1344 \mathrm{~cm}^{-1}$ was used as a measure of the concentration of $\mathrm{C}$ centers $\left(\mathrm{N}_{\mathrm{c}}\right)$ (Lawson et al. 1998). An absorption coefficient of $1 \mathrm{~cm}^{-1}$ of the peak $1344 \mathrm{~cm}^{-1}$ has earlier been found to be consistent with a concentration of $41 \mathrm{ppm}$ for spectral resolution $1 \mathrm{~cm}^{-1}$ (Liggins 2010). The total nitrogen concentration, $\mathrm{N}_{\text {tot }}$, was estimated as $\mathrm{N}_{\mathrm{A}}$ plus $\mathrm{N}_{\mathrm{C}}$ concentration; also the share of nitrogen in A centers $\mathrm{N}_{\mathrm{AS}}(\%)$ was calculated as $\mathrm{N}_{\mathrm{A}} / \mathrm{N}_{\text {tot }}$. In the results, the concentration values were rounded to $5 \mathrm{ppm}$ because of the crystals heterogeneity and errors in decomposition of the spectra. In this study, an absorption coefficient at $1332 \mathrm{~cm}^{-1}$ was measured after subtracting of A-defects band from the absorption spectra. The baseline for peak $1332 \mathrm{~cm}^{-1}$ was obtained by linear averaging of absorbance at the range $1350-1430 \mathrm{~cm}^{-1}$. Absorption at $1332 \mathrm{~cm}^{-1}$ is typical of most impurity defects inducing IR absorption, but as an individual peak it is considered to be induced by positively charged C centers, i.e. X-centers (Lawson and Kanda 1993). The absorption coefficient of the band $3107 \mathrm{~cm}^{-1}\left(\alpha_{3107}\right)$ was measured, which is consistent with the defect $\mathrm{V}_{3} \mathrm{NH}$ (Goss et al. 2014).

Photoluminescence spectra were recorded on a Renishaw In Via spectrometer at $77 \mathrm{~K}$ upon laser excitation $\left(\lambda_{\text {ex }}\right)$ with wavelengths of $405,450,488$ and $787 \mathrm{~nm}$, a L50 $\times$ objective, in the range of $410-1050 \mathrm{~nm}$. When analyzing the PL spectra, the predominant lines were indicated. Generally if several systems overlap each other, it is often impossible to analyze them separately. For example, the narrow lines of the systems $\mathrm{H} 3,3 \mathrm{H}$ and $\mathrm{S} 1$ are $\sim 503 \mathrm{~nm}$. In case of the intensive system $\mathrm{H} 3$, other lines may not be distinguished. In the current study, heterogeneities in PL were visualized using a Leica M205 microscope at a $\lambda_{\text {ex }} 405 \mathrm{~nm}$ through an edge 450 $\mathrm{nm}$ long-pass filter.

\section{Results}

Three groups of crystals have been identified differing in the color and heterogeneity of PL (Fig. 1). The groups are categorized as: 1) crystals with homogeneous red PL; 2) crystals with faint red or red PL in the center and blue or green PL at the periphery; 3) crystals with yellow PL in the center and blue or green $\mathrm{PL}$ at the periphery. In addition to the core/periphery heterogeneity, most of the crystals display a thin zoning in the distribution of nitrogen and hydrogen defects and some PL systems. The averaged parameters for core/periphery zones are discussed per group below and are summarized in the Tab. 1. All the raw FTIR spectra are available in the Electronic supplementary material (ESM 1).

\subsection{Group 1}

In the spectra of the first group of crystals, absorbance in the visible range increases continuously from low wavelengths (Fig. 2a). The absorption spectra of the central and peripheral zones differ only in the amplitude. In absorption there is a line at $614 \mathrm{~nm}$, which is also seen in PL spectra as a reabsorption (Fig. 2a, c). Nitrogen is present dominantly as $\mathrm{C}$ centers with main peak at $1135 \mathrm{~cm}^{-1}$. The precise position of this maximum is shifted up to 1140 $\mathrm{cm}^{-1}$ in spectra with intense peak $1332 \mathrm{~cm}^{-1}$. The absorbance of the bands with maxima of $1344 \mathrm{~cm}^{-1}$ and 1332 $\mathrm{cm}^{-1}$ are close (Fig. 2b). At the periphery of the crystals of this group, the values of $\mathrm{N}_{\text {tot }}, \mathrm{N}_{\mathrm{C}}$ and $\mathrm{a}_{1332}$ are smaller than those in the core. The first group of crystals has 905 $\mathrm{nm}$ and $986 \mathrm{~nm}$ bands (H2) in PL spectra at a $\lambda_{\text {ex }} 787$ $\mathrm{nm}$. These bands are also observed in absorption spectra. Upon excitation at $405 \mathrm{~nm}$, the PL spectra are dominated by a wide structureless band with a maximum of about $600 \mathrm{~nm}\left(\mathrm{BB}_{600}\right)$ and bands at 575 and $638 \mathrm{~nm}(\mathrm{NV}$ and $\mathrm{NV}^{-}$) and a $689 / 698 \mathrm{~nm}$ pair, sometimes with a line at 685 $\mathrm{nm}$. Upon excitation at $450 \mathrm{~nm}$, system $\mathrm{H} 3$ excited more effectively, and lines $689 / 698 \mathrm{~nm}$ dominate the spectra. In the FTIR spectra of this group, $a_{3107}$ is either less than $0.1 \mathrm{~cm}^{-1}$ or is not distinguished. The absorption spectra of several samples display structured absorption systems with local maxima at 1265 and $1300 \mathrm{~cm}^{-1}$ and many bands in the ranges of $1330-1750$ and $2800-3300 \mathrm{~cm}^{-1}$ designated earlier respectively as F- and Y-centers (Clark and Davey 1984; Hainschwang et al. 2012). The crystals with the $\mathrm{F}$ - and Y-centers have a set of sharp PL lines in the range $800-900$ at a $\lambda_{\text {ex }} 787 \mathrm{~nm}$ (Fig. 2c). The set is not excited by 405,450 and $488 \mathrm{~nm}$ lasers. The lines position and intensity continuously change during spectra acquisition. At room temperature, the lines intensity decreases, but their width increases. The identification of the origin of these lines will be the topic of further research.

\subsection{Group 2}

The crystals of the second group display zonal PL. The contour of the absorption spectra in the visible range is the same as that of the crystals of the first group (Fig. 3a). Nitrogen in the crystals of the second group is present predominantly as A centers, but the concentration of $\mathrm{C}$ centers in the core is higher than that in the periphery. The absorbance of the $1332 \mathrm{~cm}^{-1}$ band is higher than that of the $1344 \mathrm{~cm}^{-1}$ band (Fig. 3b). In the spectra of the peripheral parts of the plates IST II-20 and IST 2-9 was recorded a band with the $4170 \mathrm{~cm}^{-1}$ maximum. This band is characteristic of crystals with signs of plastic deformation. The central zone of the plates exhibits red PL; in some cases it is not visually identifiable because the intensity is small. The periphery of the crystals emits either blue or green PL. The 


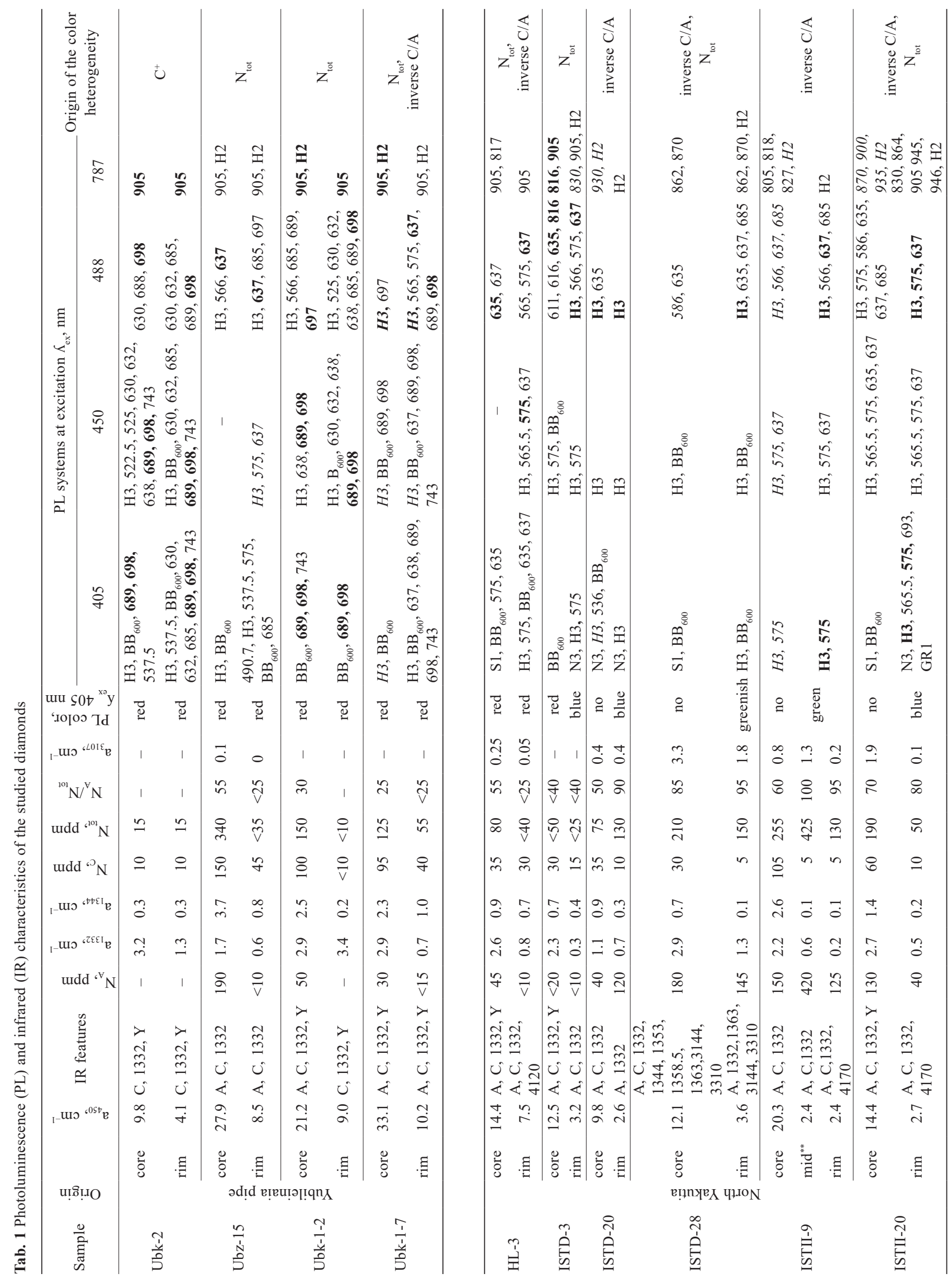




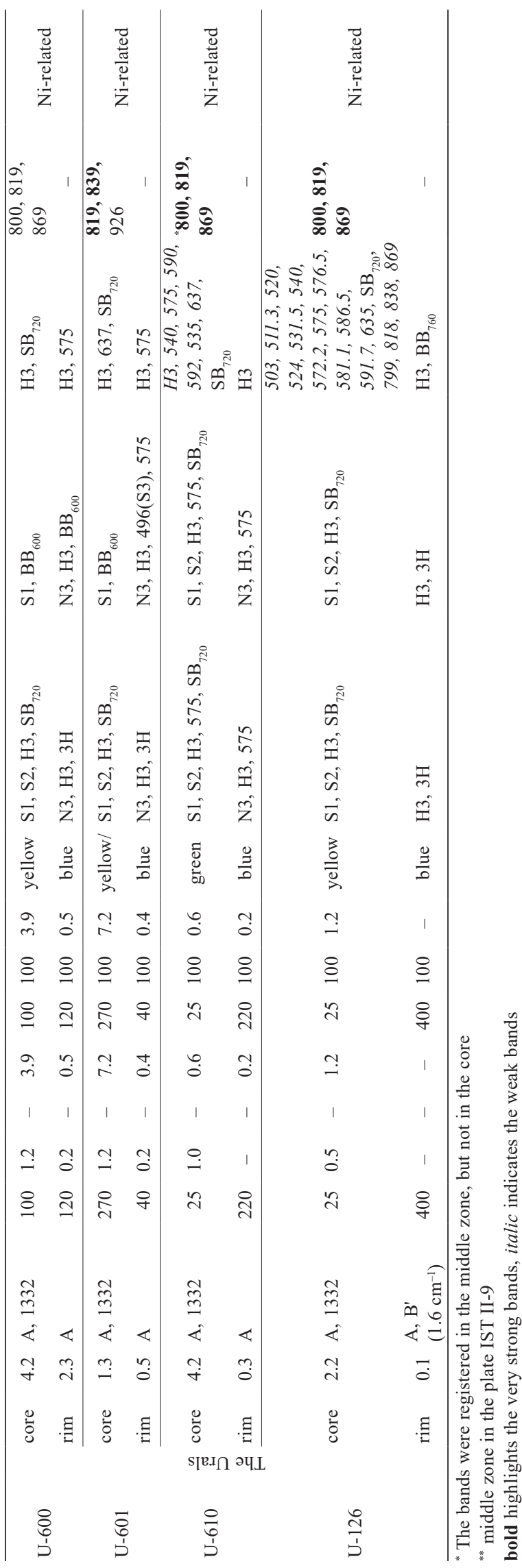

$\mathrm{N} 3$ and $\mathrm{H} 3$ systems, 575 and $638 \mathrm{~nm}$ bands are recorded in these zones (Fig. 3c). The N3 system is absent in the spectra of the crystal cores. A broad band with a maximum of 600 $\mathrm{nm}$, lines 575 and $638 \mathrm{~nm}$ is revealed. Two crystals have a $565 \mathrm{~nm}$ line and one crystal has 552, 685 and $689 \mathrm{~nm}$ lines. Upon $787 \mathrm{~nm}$ excitation, the PL spectra of all crystals display a $\mathrm{H} 2$ system. The PL spectra of various crystals of this group differ from each other. They all exhibit a variety of weak peaks at $805,816,827,830,864,870,900,905$, 930 , and $945 \mathrm{~nm}$. The origin of the bands is still unknown.

\subsection{Group 3}

Crystals of the third group display yellow PL in the center and either blue or green PL at the periphery. The color of crystals is canary-yellow. Crystals U 600 and U 601 are well-developed cuboids; crystals U610 and U126 are chips of cuboids. In rims of the latter are clearly seen linear blue zones. These imply a change in the growth mechanism from normal $\{100\}$ to tangential $\{111\}$. In third group, nitrogen is present as A centers. The $1344 \mathrm{~cm}^{-1}$ band of $\mathrm{C}$-defect is not recorded in the FTIR spectra; and neither are the bands of $Y$ centers. In the peripheral part of the plate U-126, a weak peak of B' was revealed. General appearance and characteristics of the absorption spectrum in the visible range differ from those of the crystals of the first and second groups. The absorption spectrum of the colored zone displays an increase in absorption from 600 $\mathrm{nm}$, a wide structureless band at 430-530 nm (Fig. 4a), and a system with peaks at 425 and $416 \mathrm{~nm}$. These spectra are similar to those described earlier in some yellow diamonds (Reinitz et al. 1998; Hainschwang et al. 2005). In the absorption spectrum of the peripheral zone of sample $\mathrm{U} 600$, there is an N3 system with an absorption coefficient of $0.2 \mathrm{~cm}^{-1}$ at $415 \mathrm{~nm}$, although such an absorption lacks in the center of the crystal. In FTIR spectra of the colored zones, there is the $1332 \mathrm{~cm}^{-1}$ peak on the background of the absorption of A centers (Fig. 4b).

The PL spectra of the colored zone at $\lambda_{\mathrm{ex}} 405 \mathrm{~nm}$ exhibit a wide band with a maximum of $600 \mathrm{~nm}$ and 503.2 and $510.5 \mathrm{~nm}$ peaks of S1 system (Fig. 4c). Upon excitation of $450 \mathrm{~nm}, \mathrm{H} 3$ system and 518, $524 \mathrm{~nm}$ peaks of the S2 system are recorded. Upon excitation of $488 \mathrm{~nm}$, the spectrum is dominated by a wide structured system with a maximum of c. $700 \mathrm{~nm}\left(\mathrm{SB}_{700}\right)$. This band was earlier observed in PL spectra of canary-yellow stones (Collins and Mohammed 1982). At $\lambda_{\mathrm{ex}}$ of $787 \mathrm{~nm}$, systems with a zero-phonon line (ZPL) at 799.5, 819.6, 869.5 and $930 \mathrm{~nm}$ are recorded. These systems have not been observed earlier (Dishler 2012; Hainschwang et al. 2013). A system with ZPL 799.5 $\mathrm{nm}$ has phonon replicas at $812,825.5$ and $839 \mathrm{~nm}$ (energy shift of $0.024 \mathrm{eV}$ ); a system with ZPL $819.6 \mathrm{~nm}$ has replicas at 839 and $859 \mathrm{~nm}$ (shift of $0.035 \mathrm{eV}$ ); a system with a ZPL of $869.5 \mathrm{~nm}$ has replicas at 891, 913 and $936 \mathrm{~nm}$ 
(shift of $0.033 \mathrm{eV}$ ); and a system with a ZPL of $930 \mathrm{~nm}$ has replicas at 952 and $975 \mathrm{~nm}$ (shift of $0.030 \mathrm{eV}$ ). They are very weak or absent in PL spectra of the colorless peripheral zone of the crystals. These systems have not been seen in the absorption spectra. The blue luminescence of N3 defects is recorded at $\lambda_{\text {ex }} 405 \mathrm{~nm}$ at PL spectra of the peripheral zones. The three zones can be distinguished from the distribution of spectral characteristics in the crystals U600 and U601 as: 1) a yellow core with intense PL with a maximum of $c$. $700 \mathrm{~nm}$ and with an absorption at 1332 $\left.\mathrm{cm}^{-1} ; 2\right)$ a colorless transition zone with a weak PL of H3; and 3) a peripheral zone with the well-defined boundary of blue luminescence of N3 system. The value of $a_{3107}$ in the transition zone is the same as that in the core, but in the peripheral zone it is lower by one order of magnitude.

\section{Discussion}

The crystals that have been studied fall into three groups, distinguished by the combination and distribution of spectroscopic characteristics (Tab. 1). The first attribute for the crystals classification was PL color and heterogeneity; the second was absorbance at 1332 and $1344 \mathrm{~cm}^{-1}$. In spectra of crystals of the first and second groups, both 1332 and $1344 \mathrm{~cm}^{-1}$ lines were observed. In the spectra of crystals of the third group only the band $1332 \mathrm{~cm}^{-1}$ was detected. Another sign of the third group is PL bands in the visible and NIR range. The main features of the groups are related to their nitrogen content.

\section{1. $N$ defects and color}

In cuboids, $\mathrm{C}$ center is the main cause of yellow coloration. In Fig. 5a, a dependence of the absorbance at 450 $\mathrm{nm}$ is shown on the $\mathrm{C}$ centers concentration. The linear character of the dependence confirms this observation. In the graph, the two sublinear groups of points are distinguished. The upper group refers to the core of the crystals; the lower one to the rims. In Fig. 5a, points for the Uralian diamonds lie on the ordinate axis because of the absence of $\mathrm{C}$ centers.
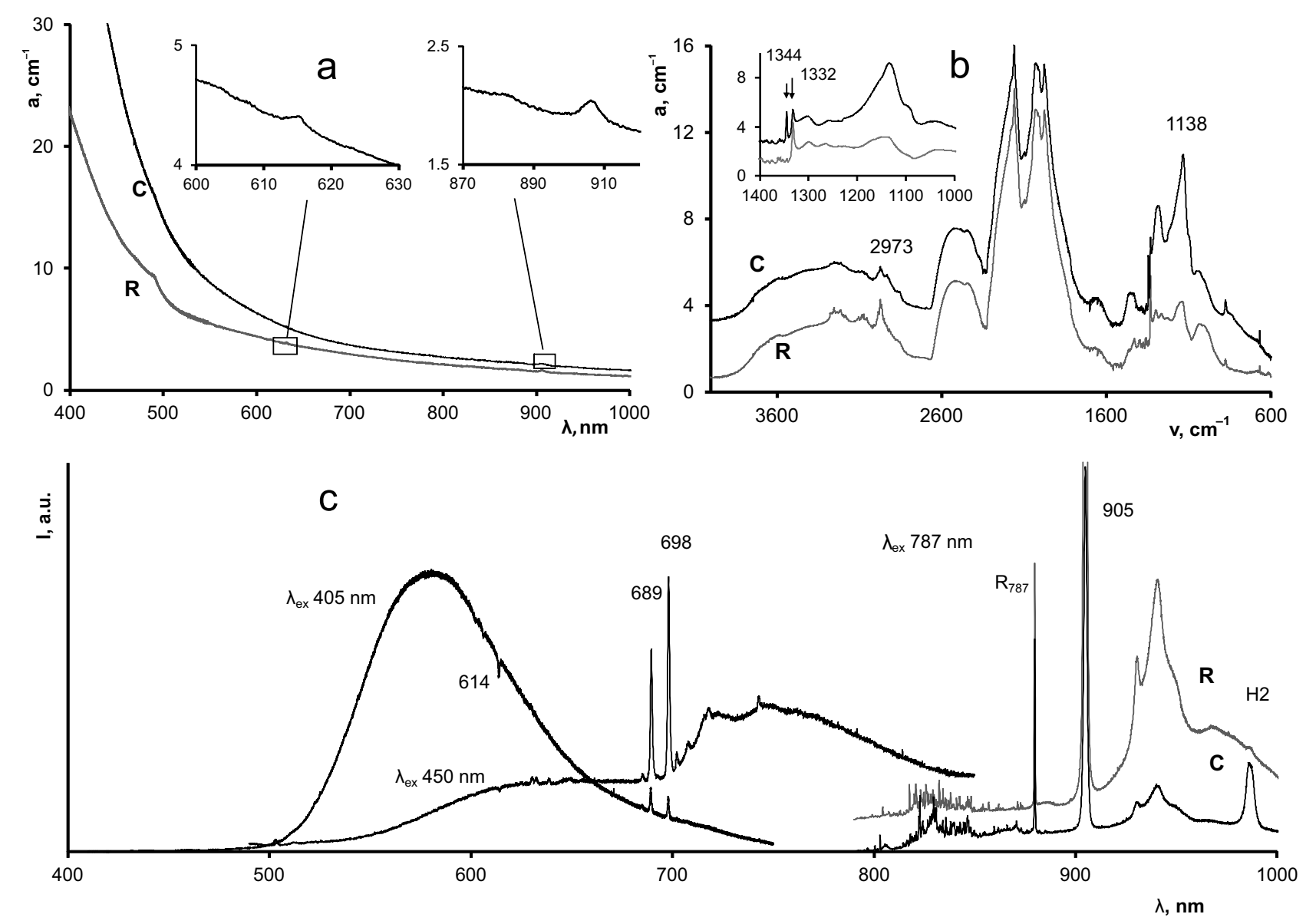

Fig. 2 Spectra of the plate Ubk1-2: a - Absorption in visible range; the inset shows lines at 614 and $905 \mathrm{~nm}$; $\mathbf{b}$ - Absorption in the IR range, the inset shows spectra after subtraction of the A centers absorption; $\mathbf{c}$ - Photoluminescence under 405, 450 and $787 \mathrm{~nm}$ excitation at $77 \mathrm{~K}$. Letters $\mathbf{C}$ and $\mathbf{R}$ mark the spectra of the core and rim, respectively. The spectra have been adjusted vertically to avoid intersection of curves. 
Figure $5 \mathrm{~b}$ shows the trends from core to rim of the absorbance at $450 \mathrm{~nm}$ and $1332 \mathrm{~cm}^{-1}$. The comparison of Fig. 5a and $b$ reveals the effect of both $\mathrm{C}$ centers and centers with the line $1332 \mathrm{~cm}^{-1}$ on the color intensity. In the crystal of the first group, the color zoning is due to $\mathrm{C}$ centers and $\mathrm{N}_{\text {tot }}$. The color brightness is proportional to nitrogen concentration, with brighter colors and higher nitrogen concentrations present in the central parts of the crystals. This case is consistent with the well-established consequence of nitrogen centers transformation: it is just a function of heterogeneity in the nitrogen content.

In the crystals of the second group, the concentration of $\mathrm{C}$ centers in the core is higher than that at the periphery. The concentration $\mathrm{N}_{\mathrm{A}}$ and the $\mathrm{N}_{\mathrm{AS}}$ at the periphery are higher. It is known that a few of the A centers in synthetic crystals may display a growth origin (Palyanov et al. 1997; Babich et al. 2000). However, the synthetic crystals are formed by the pyramids [111], [100], [110], [113], [115], and their growth mechanism is tangential (Collins and Dahwich 2003). It is not clear whether nitrogen in the form of A centers can become a part of the structure upon the normal growth of $\{100\}$ faces. The possibility of the growth origin of a few A centers should be taken into account, because it could be responsible for some of the results obtained. A few of the A centers in the crystals of the second group may have formed directly during the growth of the crystals, rather than by transformation of the $\mathrm{C}$ centers.

The FTIR spectra of the crystals of the third group have a $1332 \mathrm{~cm}^{-1}$ band but no $1344 \mathrm{~cm}^{-1}$ band of $\mathrm{C}$ centers. The former band is typical of positively charged $\mathrm{C}+$ centers (Lawson et al. 1998). It has been shown that as a result of electron irradiation (Lawson et al. 1998), as well as UV exposure (Khan et al. 2010), the amplitude of the $1344 \mathrm{~cm}^{-1}$ band decreases and that of the $1332 \mathrm{~cm}^{-1}$ band increases. However, the absorption at the $1332 \mathrm{~cm}^{-1}$ is present in the spectra induced by all impurity defects such as nitrogenous $\mathrm{C}, \mathrm{A}, \mathrm{B}$, platelets $\mathrm{B}^{\prime}$ and boron atoms (Zaitsev 2001). The wavenumber $1332 \mathrm{~cm}^{-1}$ is consistent with maximum phonon energy in the center of the Brillouin zone. The presence of either impurities or internal defects, which locally decrease symmetry, induces absorption at this wavenumber (Birman 1974). Therefore, the $1332 \mathrm{~cm}^{-1}$ peak cannot be unambiguously interpreted as being consistent with the presence of the C + centers. This was noted by Lawson and Kanda (1993),
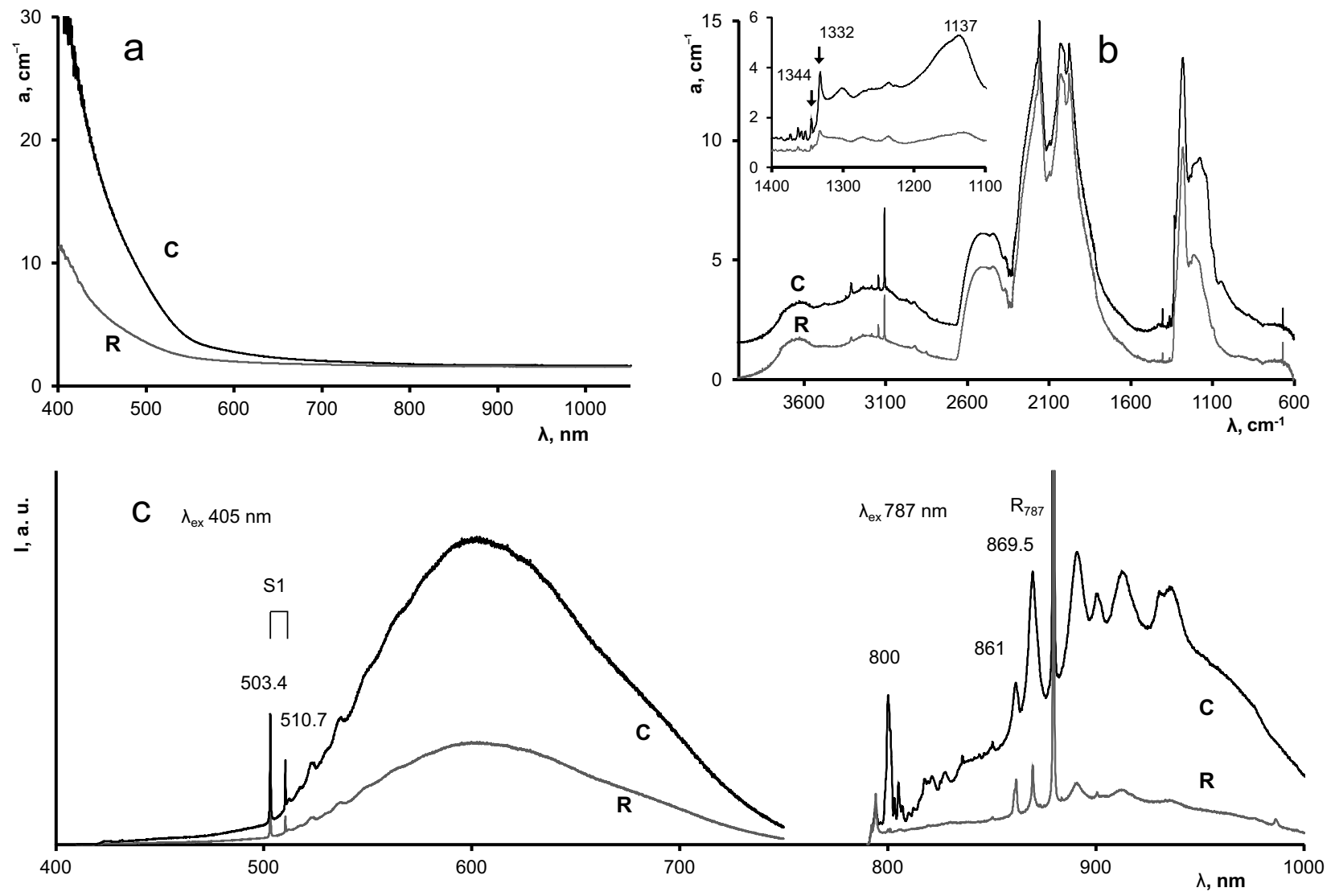

Fig. 3 Spectra of the plate ISTD-28: a - Absorption in visible range; $\mathbf{b}$ - Absorption in the IR range, the inset shows spectra after subtraction of the A centers absorption; $\mathbf{c}$ - Photoluminescence under $405 \mathrm{~nm}$ and $787 \mathrm{~nm}$ excitation at $77 \mathrm{~K}$. Letters $\mathbf{C}$ and $\mathbf{R}$ mark the spectra of the core and rim, respectively. The spectra have been adjusted vertically to avoid intersection of curves. 
who demonstrated that the $1332 \mathrm{~cm}^{-1}$ band is typical of various point defects. This fact seems to be responsible for the ambiguous interpretation of a few experimental results (Lawson and Kanda 1993; Fisher and Lawson 1998; Kiflawi et al. 1998), in which the $1332 \mathrm{~cm}^{-1}$ band amplitude has been accepted to be proportional to the $\mathrm{Ni}$ concentration.

\section{2. $N$ defects and natural annealing}

The experimental points of $\mathrm{N}_{\text {tot }}$ and $\mathrm{N}_{\mathrm{AS}}$ in the studied diamond are shown in Fig. 6. The isotherms therein were calculated for duration of annealing (mantle residence time) of 10 years, using the calibration data of Chrenko et al. (1977). The temperatures of the isotherms are shown for annealing time $10 \mathrm{Myr}$ based on calibrations of Taylor et al. (1996) for cubic faces. The time of annealing here has no geological meaning, it just shows the range of diversity in experimental results. The values of $\mathrm{N}_{\text {tot }}$ and $\mathrm{N}_{\mathrm{AS}}$ for core and rim are shown in the plot. Arrows mark values for the rim points. Crystal Ubk-2 dos not contain
A centers, its points are at the bottom of the graph. The normal sequence is the higher model temperature for a core and the lower for a rim. It was observed in the plates Ubk1-2 and ISTD-3. In the plate UBZ 15, the core-rim trend is subparallel to the isotherms. It is clearly seen that in the other crystals of the first and second groups the rim points refer to higher isotherm than those in the core. In the plates ISTD 20 and IST 2-9 both $\mathrm{N}_{\text {tot }}$ and $\mathrm{N}_{\mathrm{AS}}$ in the rim are higher than those in the core. Crystals of the third group are disposed on the line with $\mathrm{N}_{\mathrm{AS}}$ of $100 \%$.

The experimental studies dealing with the formation kinetics of A centers are somewhat contradictory. The first value for the activation energy of the formation of A centers $(2.6 \mathrm{eV})$ was estimated by Chrenko et al. (1977). These authors inferred second-order kinetics of the formation of A centers. In later studies (Belimenko et al. 1981; Evans and Qi 1982; Kanda et al. 1990; Kiflawi and Mainwood 1996; Taylor et al. 1996), the activation energy range was estimated to be $3.6-6.0 \mathrm{eV}$. Some discrepancies arise from fact that synthetic diamonds of cubo-octahedral or cubic habit show a facetted style
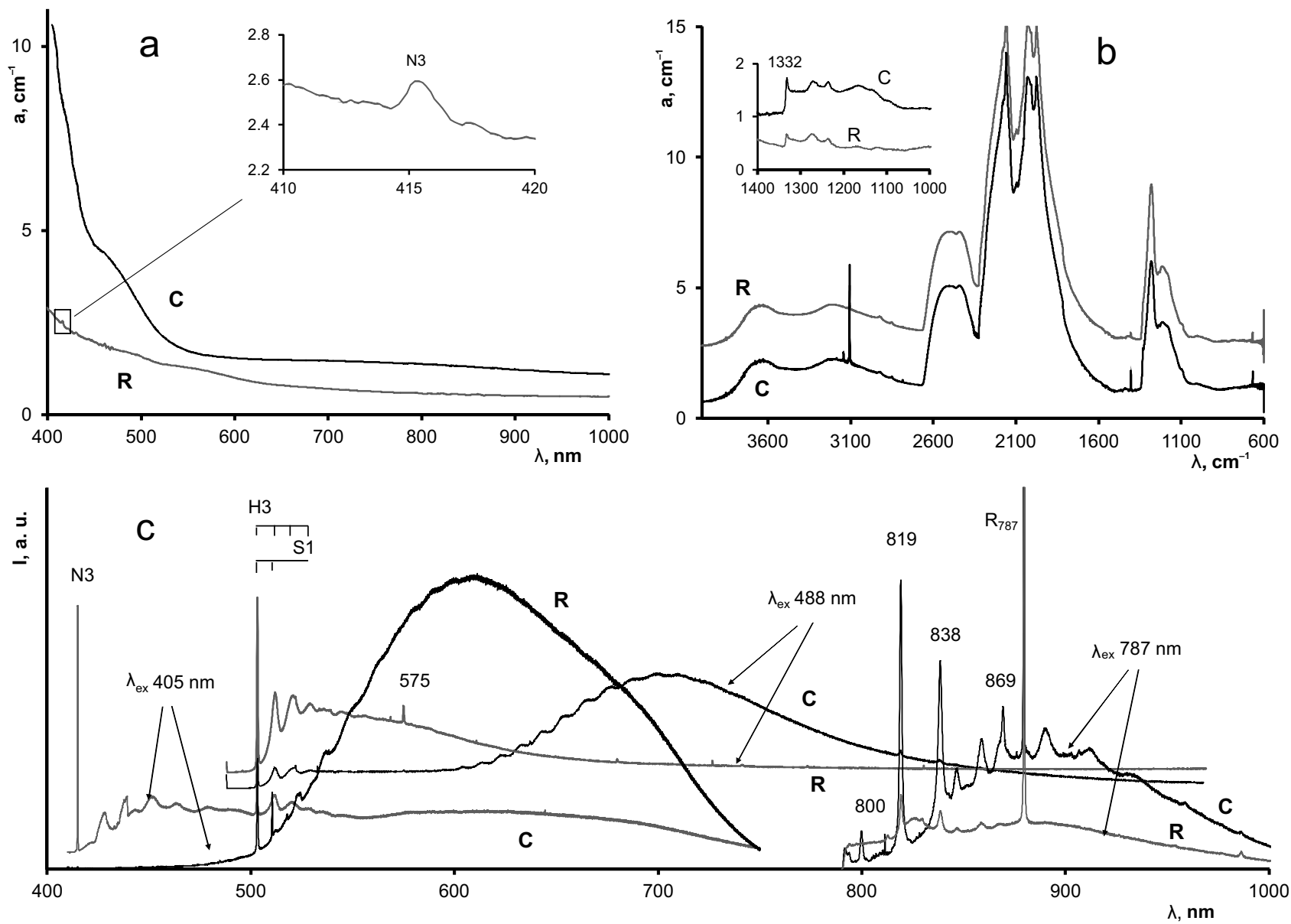

Fig. 4 Spectra of the plate U600: a - Absorption in the visible range, the inset shows line $415 \mathrm{~nm}$ of N3 center; $\mathbf{b}$ - Absorption in the IR range, the inset shows spectra after subtraction of the A centers absorption; $\mathbf{c}$ - Photoluminescence under 405, 488 and $787 \mathrm{~nm}$ excitation at $77 \mathrm{~K}$. Letters $\mathbf{C}$ and $\mathbf{R}$ mark the spectra of the core and rim, respectively. The spectra have been adjusted vertically to avoid intersection of curves. 

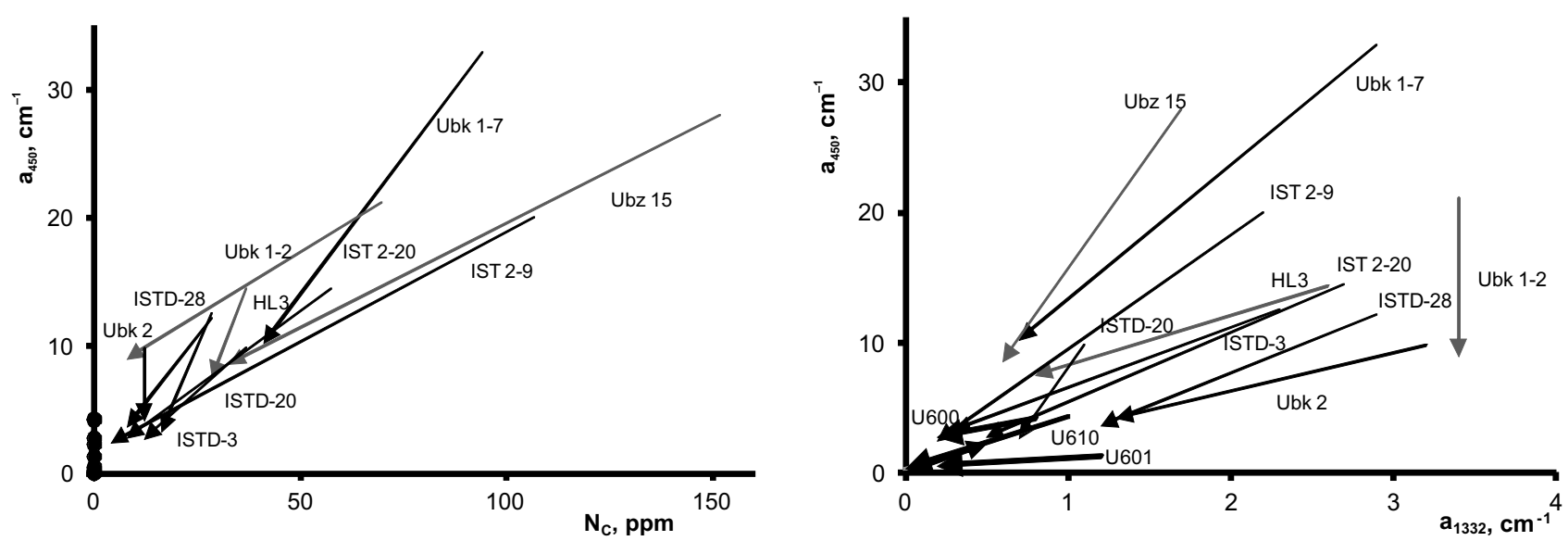

Fig. 5 A dependence of the absorbance at $450 \mathrm{~nm}$ on concentration of $\mathrm{C}$ centers (a) and on absorbance of the line $1332 \mathrm{~cm}^{-1}$ (b). Arrows mark the rim points. Grey lines refer to the diamonds with normal zoning. Black circles in (a) and bold arrows in (b) correspond to the Uralian diamonds.

of growth (Taylor et al. 1996). These were compared to natural cuboid diamonds of the non-facetted growth. The activation energy of the $\mathrm{C} \rightarrow \mathrm{A}$ reaction, as estimated by various researchers for various growth pyramids, differs substantially (Taylor et al. 1996; Collins 2001; Kazuchits et al. 2019).

It seems that the kinetics of this reaction may vary, depending on factors such as the presence of nickel or other impurities (Fisher and Lawson 1998; Kiflawi et al. 1998; Nadolinny et al. 2000; Yelisseyev and Kanda 2007), radiation (Collins 1980; Taylor et al. 1996; Kim et al. 2011; Mita et al. 2018) and plastic deformation (Nadolinny et al. 2020). The activation energy of aggregation of $\mathrm{C}$ centers into $\mathrm{A}$ center in $\mathrm{Ni}$-containing synthetic diamonds with NV centers may vary from 0.5 to $1.5 \mathrm{eV}$ depending on nitrogen concentration (Yelisseyev et al. 2011). In this research, three different mechanisms of the $\mathrm{C}$ centers aggregation were proposed. The combined effect of all mentioned factors makes it much more difficult to interpret the results obtained and to understand the processes. Thus, on the one hand, radiation stimulates the diffusion activity of impurity atoms (Collins 1980); on the other hand, the generated interstitials stabilize single nitrogen atoms (Collins and Dahwich 2003). Another complication is the irregularity of the distribution of nitrogen and delements throughout different growth pyramids (Fisher and Lawson 1998; Babich and Feigelson 2009). Several of the above-mentioned factors have been neglected while interpreting the experimental results.

The PL systems S1 and S2 are known to be due to Ni-involving centers (Dishler 2012). The system $\mathrm{SB}_{700}$ is also attributed to Ni-bearing centers (Titkov et al. 2015). Systems with maxima of $799.5,819.6,869.5$ and $930 \mathrm{~nm}$ were revealed in the spectra of cuboids from the Urals placers (Klepikov et al. 2019). In most cases, the systems were registered together with the $883 / 885$ $\mathrm{nm}$ doublet of the low-temperature $\mathrm{Ni}$ involving center.
It has been shown earlier (Yelisseyev and Kanda 2007) that $\mathrm{Ni}$ impurity stabilizes $\mathrm{N}+$ defects, by compensating the charge and decreasing their diffusion mobility. It is hereby inferred that the "inverse" distribution of color in the crystals of the third group is the result of stabilization of single nitrogen atoms by $\mathrm{Ni}$ atoms. This is the simplest interpretation based on the fact of conversion between $\mathrm{C}$ and $\mathrm{C}+$ centers, with changing intensities of lines 1344 and $1332 \mathrm{~cm}^{-1}$ respectively (Lawson et al. 1998; Khan et al. 2010).

In the crystals U600 and U601, the volume distribution of $\mathrm{N}_{3} \mathrm{~V}$ does not coincide with either color or Ni-related PL. These stones display an inverse relationship between the concentration of $\mathrm{N}_{3} \mathrm{~V}$ centers and that of hydrogenbearing $\mathrm{N}_{3} \mathrm{VH}$ centers with absorption at $3107 \mathrm{~cm}^{-1}$. Similar distributions have been observed earlier (Vasilev et al. 2019) and are interpreted to be due to the trapping of a hydrogen atom by $\mathrm{N}_{3} \mathrm{~V}$ centers and their transformation to

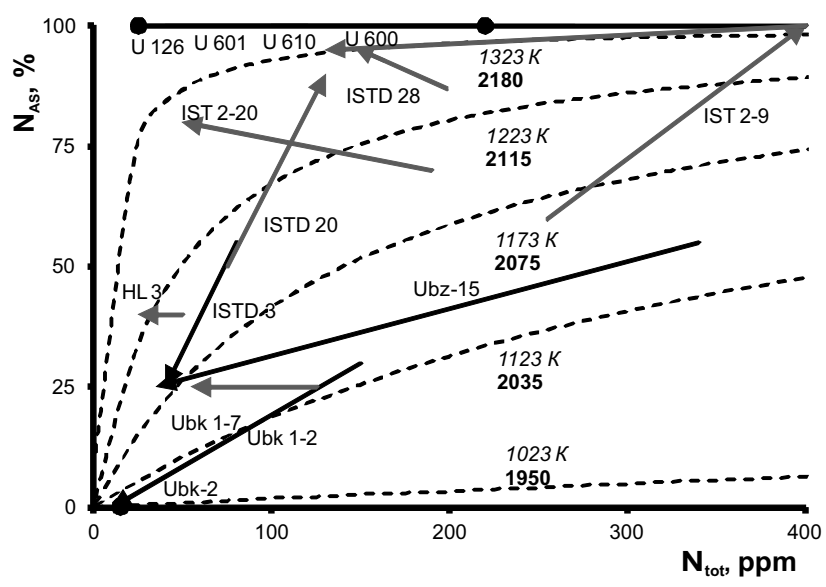

Fig. 6 Transformation of the state of nitrogen in the studied diamonds from core to rim. Arrows indicate the points in the rim zones. All diamonds of the third group from the Urals fall on the top of the diagram. Isotherms are calculated for annealing time of $10 \mathrm{yr}$ (italic) by calibrations from Chrenko et al. (1977), and for annealing time of 10 Myr (bold) using calibrations from Taylor et al. (1996) for cubic faces. 
the form $\mathrm{N}_{3} \mathrm{VH}: \mathrm{N}_{3} \mathrm{~V}+\mathrm{H} \rightarrow \mathrm{N}_{3} \mathrm{VH}$. This form is inactive in luminescence but active in IR absorption.

Hence, the study of defect distributions within crystals enables a better understanding of the transformation patterns of impurity and internal defects and reveals their genesis.

The results show an existence of some regional features in the evolution of diamond-forming systems. The yellow diamonds from conventional Yubileinaya kimberlitic pipe have the lowest model temperature or mantle residence time. These stones do not contain any of high-temperature centers B, B' or N3 and show only limited variations in nitrogen content during the crystal growth. Majority of the diamonds from Istok placer in the Anabaro-Oleneksky interfluve shows inverse distribution of nitrogen $\mathrm{A}$ and $\mathrm{C}$ centers. They contain only a few high-temperature N3 centers in peripheral parts. The diamonds from the Urals show a heterogeneity of another origin. They do not contain the simplest $\mathrm{C}$ centers, but instead rare Ni-related centers in the core, and the B, B', N3 in the periphery.

It remains unclear, what growth conditions and postgrowth treatment lead to the differentiation of diamonds in the content of Ni-related centers. Further efforts are required to find the cause of variation in $\mathrm{Ni}$ concentration upon the growth of cuboids and to reveal the nature of the observed PL systems.

\section{Conclusions}

Three types of the distribution of spectroscopic characteristics have been identified in cubic diamonds with a yellow core. The results show regional features in the studied diamonds regarding the nature of their heterogeneity.

1) The nitrogen concentrations in the C-center vary in the diamonds from the Yubileinaya pipe. This population is characterized by red photoluminescence; it has higher $\mathrm{C}$-center, total nitrogen concentrations and stronger color in the core than in the rim.

2) Complicated ("inverse") distribution of nitrogen centers was observed in the diamonds from North Yakutia. The detection of the A-centers in the periphery, and low-temperature $\mathrm{C}$-centers in the core are uncommon. This is inferred to be caused by growth origin of $\mathrm{A}$ centers, as shown previously in the case of synthetic crystals.

3) The heterogeneous Ni impurity distribution was revealed in diamonds from the Urals. Nickel atoms appear to stabilize $\mathrm{C}+$ defects, thereby affecting the color of individual zones.

Acknowledgements. We would like to thank S. C. Kohn and S. Timmerman for the helpful discussion and their insightful reviews and R. Škoda with V. Janoušek for the manuscript handling and valuable comments. This study has been supported by Russian Science Foundation grant 16-17-10067.

Electronic supplementary material. Supplementary material (raw FTIR spectra for all analyzed points) is available online at the Journal web site (http://dx.doi.org/10.3190/ jgeosci.301).

\section{References}

Babich YuV, Feigelson BN (2009) Distribution of $\mathrm{N}^{+}$centers in synthetic diamond single crystals. Inorg Mater 45: 616-619

Babich YV, Feigelson BN, Fisher D, Yelisseyev AP, NADOLINNY VA, BAKER JM (2000) The growth rate effect on the nitrogen aggregation in HTHP growth synthetic diamonds. Diamond Relat Mater 9: 893-896

Belimenko LD, Klyuev YuA, Laptev VA, Naletov AM, Nepsha VI, Samoilovich MI (1981) The effect of diamond single-crystal annealing under conditions of their thermodynamic stability on the formation and transformation of structural imperfections. Dokl Akad Nauk SSSR 259: 1360-1363

Birman JL (1974) Theory of Crystal Space Groups and Infra-Red and Raman Lattice Processes of Insulating Crystals. Springer-Verlag, Berlin, pp 1-521

Boyd SR, Mattey DP, Pillinger CT, Milledge HJ, MenDELSSOHN M, SEAT M (1987) Multiple growth events during diamond genesis: an integrated study of carbon and nitrogen isotopes and nitrogen aggregation state in coated stones. Earth Planet Sci Lett 86: 341-357

Boyd SR, KifLawi I, Woods GS (1994) The relationship between infrared absorption and the A defect concentration in diamond. Philos Mag B 69: 1149-1153

Bulanova GP, Pearson DG, Hauri EH, Griffin BJ (2002) Carbon and nitrogen isotope systematics within a sectorgrowth diamond from the Mir kimberlite, Yakutia. Chem Geol 188: 105-123

Chrenko RM, Tuft RE, Strong U (1977) Transformation of the state of nitrogen in diamond. Nature 270: 141-144

Clark CD, Davey ST (1984) One-phonon infrared absorption in diamond. J Phys C: Solid St Phys 17: 1127-1140

ColLINS AT (1980) Vacancy enhanced aggregation of nitrogen in diamond. J Phys C: Solid St Phys 13: 2641-2650

Collins AT (2001) The colour of diamond and how it may be changed. J Gemm 27: 341-359

Collins AT, DAHWICH A (2003) The production of vacancies in type Ib diamond. J Phys Condens Matter 15: L591-L596

Collins AT, Mohammed K (1982) Optical studies of vibronic bands in yellow luminescing natural diamonds. J Phys C: Solid St Phys 15: 147-158 
DisHLER B (2012). Handbook of Spectral Lines in Diamond. Springer-Verlag, Berlin, pp 1-467

Evans T, QI Z (1982) The kinetics of the aggregation of nitrogen atoms in diamond. Proc R Soc London, Ser A 381: 159-178

FISHER D, LAWSON SC (1998) The effect of nickel and cobalt on the aggregation of nitrogen in diamond. Diamond Relat Mater 7: 299-304

Goss JP, Briddon PR, HiLl V, Jones R, Rayson MJ (2014) Identification of the structure of the $3107 \mathrm{~cm}^{-1} \mathrm{H}$-related defect in diamond. J Phys Condens Matter 26: 1-6

Gubanov N, Zedgenizov D, Sharygin I, Ragozin A (2019) Origin and evolution of high-Mg carbonatitic and low-Mg carbonatitic to silicic high-density fluids in coated diamonds from Udachnaya kimberlite pipe. Minerals 9: 734

Hainschwang T, Simic D, Fritsch E, Deluanin B, WoODRING S, DELRE N (2005) A gemological study of a collection of chameleon diamonds. Gems Gemol 1: 20-35

Hainschwang T, Notari F, Fritsch E, Massi L (2006) Natural, untreated diamonds showing the A, B and $\mathrm{C}$ infrared absorptions ("ABC diamonds"), and the $\mathrm{H} 2$ absorption. Diamond Relat Mater 15: 1555-1564

Hainschwang T, Fritsch E, Notari F, Rondeau B (2012) A new defect center in type Ib diamond inducing one phonon infrared absorption: the Y center. Diamond Relat Mater 21: 120-126

Hainschwang T, Karampelas S, Fritsch E, Notary F (2013) Luminescence spectroscopy and microscopy applied to study gem materials: a case study of $\mathrm{C}$ centre containing diamonds. Mineral Petrol 107: 393-413

KamiYa Y, LANG AR (1965) On the structure of coated diamonds. Philos Mag 11: 347-356

Kanda H, Ohsawa T, Yamaoka S (1990) Formation of nitrogen pairs in synthetic diamond during growth. In: Saito S, Fukunaga O, Yoshikawa M (eds) Science and Technology of New Diamond. Terra Scientific Publishing, Tokio, pp 339-344

Kazuchits NM, Rusetsky MS, Kazuchits VN, KoroliK OV, Kumar V, Moe KS, Wang W, Zaitsev AM (2019) Comparison of HPHT and LPHT annealing of Ib synthetic diamond. Diamond Relat Mater 91: 156-164

Khan R, Martineau PM, Cann BL, Newton ME, Dhillon HK, Twitchen DJ (2010) Color alterations in CVD synthetic diamond with heat and UV exposure: implications for color grading and identification. Gems Gemol 1:18-26

Kiflawi I, Mainwood A (1996) Nitrogen interstitials in diamond. Phys Rev B 54: 16719-16726

Kiflawi I, Kanda H, Mainwood A (1998) The effect of nickel and the kinetics of the aggregation of nitrogen in diamond. Diamond Relat Mater 7: 327-332

Kim JR, Kim DK, ZhU H, AbBaschian R (2011) High pressure and high temperature annealing on nitrogen aggregation in lab-grown diamonds. J Mater Sci 46: 6264-6272
King JM, Shigley JE, Gelb TH, Guhin SS, HALl M, WANG W (2005) Characterization and grading of natural-color yellow diamonds. Gems Gemol 2: 88-115

Klepikov IV, Vasilev EA, Antonov AV (2019) Defect and admixture composition of diamond crystals with growth pyramids $<100>$ from placers of the Krasnovichersky district, the Urals. Proc Russian Miner Soc 5: 59-72

Kohn SC, Speich L, Smith CB, Bulanova GP (2016) FTIR thermochronometry of natural diamonds: a closer look. Lithos 265: 148-158

Lai MY, Stachel T, Breeding CM, Stern AR (2020) Yellow diamonds with colourless cores - evidence for episodic diamond growth beneath Chidliak and the Ekati Mine, Canada. Mineral Petrol 114: 91-103

LAWSON SC, KANDA H (1993) An annealing study of nickel point defects in high-pressure synthetic diamond. J Appl Phys 73: 3967-3973

Lawson CS, Fisher D, Hunt DC, Newton ME (1998) On the existence of positively charged single-substitutional nitrogen in diamond. J Phys Condens Matter 10: 6171-6180

Liggins S (2010) Identification of Point Defects in Treated Single Crystal Diamond. Unpublished PhD. thesis, University of Warwick, pp 1-241

Mita Y, Nisida Y, OKada M (2018) Formation of the nitrogen aggregates in annealed diamond by neutron irradiation. AIP Adv 8: 025106

Nadolinny VA, Yelisseyev AP, Baker JM, Twitchen DJ, Newton ME, Feigelson BN, Yuryeva OP (2000) Mechanisms of nitrogen aggregation in nickel- and cobalt-containing synthetic diamonds. Diamond Relat Mater 9: 883-886

NADOLINNy VA, Shatsky VS, YuRYEVA OP, RaKhMANOVA Mi, Komarovskikh AYu, Kalinin AA, Palyanov YuN (2020) Formation features of N3V centers in diamonds from the Kholomolokh placer in the Northeast Siberian Craton. Phys Chem Miner 47:4

Palyanov YN, Khokhryakov AF, Borzdov YuM, Sokol AS, Gusev VA, Rylov GM, Sobolev NV (1997) Growth conditions and real structure of synthetic diamond crystals. Rus Geol Geophys 5: 882-906

Reinitz M, Fritsch E, Shigley JE (1998) An oscillating visible light optical center in some natural green to yellow diamonds. Diamond Relat Mater 7: 313-316

Smit KV, D'HaEnens-JohansSOn UFS, Howell D, LOUdIN LC, WANG W (2018) Deformation-related spectroscopic features in natural Type Ib-IaA diamonds from Zimmi (West African Craton). Mineral Petrol 112: 243-257

Taylor WR, Canil D, Milledge HJ (1996) Kinetics of Ib to IaA nitrogen aggregation in diamond. Geochim Cosmochim Acta 23: 4725-4733

Timmerman S, Chinn IL, Fisher D, Davies GR (2018) Formation of unusual yellow Orapa diamonds. Mineral Petrol 112: 209-218 
Titkov SV, Shiryaev AA, Zudina NN, Zudin NG, SoloDovA YuP (2015) Defects in cubic diamonds from the placers in the northeastern Siberian Platform: results of IR microspectrometry. Rus Geol Geophys 1-2: 354-362

VASILEv EA, SofroneEv SV (2007) Zoning of diamonds from the Mir kimberlite pipe: results of Fourier-transformed infrared spectroscopy. Geol Ore Depos 49: 784-791

Vasilev E, Kozlov A, Petrovsky V, Antonov A, KudRiavtsev A, Orekhova K (2019) The story of one diamond: the heterogeneous distribution of the optical centres within a diamond crystal from the Ichetju placer, northern Urals. Mineral Mag 4: 515-522

YELISSEYEV AP, KANDA H (2007) Optical centers related to $3 \mathrm{~d}$ transition metals in diamond. New Diamond Front Carbon Technol 3: 127-178
Yelisseyev AP, Pokhilenko NP, Steeds JW, Zedgenizov DA, AFANASIEV VP (2004) Features of coated diamonds from the Snap Lake/King Lake kimberlite dyke, Slave Craton, Canada, as revealed by optical topography. Lithos 1-4: 83-97

Yelisseyev AP, Vins VG, Lobanov SS, Maximov AYu (2011) Aggregation of donor nitrogen in irradiated Ni-containing synthetic diamonds. J Cryst Growth 1: 539-544

ZAITSEv AM (2001) Optical Properties of Diamond: A Data Handbook. Springer, New York, pp 1-502

Zedgenizov DA, Kalinina VV, Reutsky VN, Yuryeva OP, RAKHMANOVA MI (2016) Regular cuboid diamonds from placers on the northeastern Siberian Platform. Lithos 265: 125-137 